\section{OPEN ACCESS}

Edited by:

Anita Luise Michel,

University of Pretoria, South Africa

Reviewed by:

Steven Olsen,

National Animal Disease Center (USDA ARS), United States David O'Callaghan,

Université de Montpellier, France

${ }^{*}$ Correspondence:

Stefan Schwarz

stefan.schwarz@fu-berlin.de

Specialty section:

This article was submitted to

Public Health Education and Promotion,

a section of the journal

Frontiers in Public Health

Received: 29 January 2021 Accepted: 23 June 2021 Published: 30 July 2021

Citation:

Jamil T, Khan AU, Saqib M. Hussain MH, Melzer F, Rehman A Shabbir MZ, Khan MA, Ali S, Shahzad A, Khan I, lqbal M, Ullah Q, Ahmad W, Mansoor MK, Neubauer H and Schwarz S (2021) Animal and Human Brucellosis in Pakistan.

Front. Public Health 9:660508. doi: 10.3389/fpubh.2021.660508

\title{
Animal and Human Brucellosis in Pakistan
}

\author{
Tariq Jamil 1,2, Aman Ullah Khan 1,3, Muhammad Saqib ${ }^{4}$, Muhammad Hammad Hussain ${ }^{5}$, \\ Falk Melzer ${ }^{1}$, Abdul Rehman ${ }^{6}$, Muhammad Zubair Shabbir ${ }^{7}$, Mumtaz Ali Khan ${ }^{8}$, \\ Shahzad Ali ${ }^{9}$, Asim Shahzad ${ }^{10}$, lahtasham Khan ${ }^{11}$, Mudassar Iqbal ${ }^{10}$, Qudrat Ullah ${ }^{12}$, \\ Waqas Ahmad ${ }^{13}$, Muhammad Khalid Mansoor ${ }^{10}$, Heinrich Neubauer ${ }^{1}$ and \\ Stefan Schwarz ${ }^{2 *}$
}

${ }^{1}$ Institute of Bacterial Infections and Zoonoses, Friedrich-Loeffler-Institut, Jena, Germany, ${ }^{2}$ Institute of Microbiology and Epizootics, Freie Universität Berlin, Berlin, Germany, ${ }^{3}$ Section of Microbiology, Department of Pathobiology, University of Veterinary and Animal Sciences, Lahore, Pakistan, ${ }^{4}$ Department of Clinical Medicine and Surgery, Faculty of Veterinary Science, University of Agriculture, Faisalabad, Pakistan, ${ }^{5}$ Independent Researcher, Bardia, NSW, Australia, ${ }^{6}$ Department of Epidemiology and Public Health, Faculty of Veterinary Science, University of Veterinary and Animal Sciences, Lahore, Pakistan, ${ }^{7}$ Institute of Microbiology, University of Veterinary \& Animal Sciences, Lahore, Pakistan, ${ }^{8}$ Field Epidemiology and Disease Survillence Division, National Institute of Health (NIH), Islamabad, Pakistan, ${ }^{9}$ Wildlife Epidemiology and Molecular Microbiology Laboratory (One Health Research Group), Discipline of Zoology, Department of Wildlife \& Ecology, University of Veterinary and Animal Sciences, Lahore, Pakistan, ${ }^{10}$ Faculty of Veterinary and Animal Sciences, The Islamia University of Bahawalpur, Bahawalpur, Pakistan, " Section of Epidemiology and Public Health, Department of Clinical Sciences, University of Veterinary and Animal Sciences, Lahore, Pakistan, ${ }^{12}$ Faculty of Veterinary and Animal Sciences, Gomal University, Dera Ismail Khan, Pakistan, ${ }^{13}$ Department of Clinical Sciences, University College of Veterinary and Animal Sciences, Narowal, Pakistan

Brucellosis is a bacterial zoonotic disease that affects many animal species and can be transmitted to humans via direct contact or via contaminated food. Although brucellosis is a serious health hazard, its public health concern has been neglected in many countries. In some developing countries, such as Pakistan, where brucellosis is endemic, this disease continues to be of importance. A literature search for the past 11 years (20112021) provided a comprehensive insight into brucellosis in Pakistan. In this review, particular emphasis was placed on occurrence, diagnostic tests used, and prevention, treatment, and control in the context of the "One Health" approach.

Keywords: brucellosis, epidemiology, zoonosis, One Health, diagnosis, Pakistan

\section{INTRODUCTION}

Brucellosis is an important zoonotic disease of domestic livestock and wildlife caused by bacteria of the genus Brucella (B.). These bacteria are intracellular, Gram-negative, non-motile, non-sporeforming coccobacilli. Brucellae demonstrate animal host preferences, e.g., B. melitensis primarily infects small ruminants, $B$. abortus large ruminants and wildlife, $B$. suis infects pigs, and $B$. canis infects dogs $(1,2)$; however, potential infections in non-preferred hosts are possible and these species may act as reservoir hosts (3-5). Brucellosis causes abortions in animals and fever, fatigue, and loss of fertility in humans. It is found worldwide, especially in developing and tropical countries, whereas some countries (i.e., North and Central Europe, Australia, New Zealand, Japan, and Canada) are considered free in domestic livestock $(6,7)$. Human brucellosis is more prevalent in countries where animal brucellosis is endemic, or in non-endemic countries, when people return from endemic areas after exposure (8-10). B. melitensis infections affect approximately 400,000-12,500,000 humans, annually, particularly in South-Eastern Europe, the Middle East, and Central Asia $(7,11,12)$. In animals, brucellosis is mainly transmitted by direct or indirect contact (via contaminated environment/fomites), whereas transmission to humans is mainly by ingestion 
of contaminated unpasteurized milk products or by direct exposure. After rabies, brucellosis is the second most transmissible zoonotic disease worldwide $(13,14)$. Serology remains the main diagnostic tool for brucellosis (e.g., Rose Bengal plate test (RBPT), serum agglutination test (SAT), complement fixation test (CFT), enzyme-linked immunosorbent assay (ELISA), and milk ring test (MRT)). Brucellosis can also be diagnosed by molecular detection (i.e., PCR). Isolation remains the golden standard for diagnosis but requires advanced laboratory and biosafety levels (e.g., level 3). In addition to being a notifiable disease, brucellosis is also considered a bio-threatening (category B) agent $(15,16)$.

\section{ANIMAL PRODUCTION IN PAKISTAN}

Pakistan is a South Asian country with an agriculture-based economy where the livestock subsector plays an integral role in agriculture. In 2019, the estimated livestock population of the country was 90.8 million cattle and buffaloes, 109.4 million small ruminants (sheep and goats), 1.1 million camels, and 6.1 million equines (17). This sub-sector contributed to $60.6 \%$ of the value of the agriculture sector and $11.7 \%$ of the national Gross Domestic Product (GDP) in 2019-20. Pakistan consists of seven administrative units, i.e., Punjab, Sindh, Balochistan, Khyber Pakhtunkhwa (KPK), Gilgit-Baltistan, Azad Jammu and Kashmir (AJK), and Islamabad Capital Territory (ICT). The majority of cattle and buffaloes is distributed around the irrigated areas of the country (i.e., Punjab and Sindh), whereas small ruminants are mainly distributed in the arid and semiarid areas (e.g., Baluchistan, KPK, Gilgit-Baltistan, and AJK). There is a strong animal-human relationship in Pakistan as owning livestock is not only a source of ready income but is also a symbol of financial status for institutions and individuals.

Brucellosis is considered endemic in Pakistan and has been reported in domestic ruminants (e.g., cattle, buffaloes, sheep and goats, and camels), non-ruminants (e.g., equines and dogs), wildlife, and humans. Brucellosis causes economic losses to the farmers in Pakistan, including the cost of treatment, fetal losses, infertility, reduced milk production, prolonged calving intervals, and losses due to the culling of the animals (18). To our knowledge, information concerning economic losses related to brucellosis in Pakistan is not available, but losses were estimated at US $\$ 3.4$ billion for dairy cattle and US $\$ 58.8$ million for active surveillance programs in India (19-21).

Pakistan produced 61.7 million tons of milk in 2019 and is ranked the fourth largest milk-producing country in the world. Approximately, $98 \%$ of the milk is marketed as raw milk, and the milk transport and storage practices are antiquated outside of large urban areas. Vaccination and treatment of brucellosis in animals are limited because of safety issues and are primarily practiced on animals of high economic value (21). Accidental contamination of milk (by vaccination or infection) not only poses negative economic effects on farmers but also is a public health threat. The purpose of this review was to review more recent data (previous 11 years) on brucellosis to emphasize the need for awareness programs, and to identify underlying problems related to disease control in Pakistan. Eliminating the shortcomings in current efforts will be beneficial in controlling brucellosis in Pakistan with a "One Health" perspective.

\section{LITERATURE SEARCH AND INCLUSION/EXCLUSION CRITERIA}

A literature search was done online by using the keywords "brucellosis, Brucella, Pakistan" on Google Scholar (Google LLC, Mountain View, California) search bar in March 2021. The search was limited to the past 11 years (2011-2021) to generate contemporary data on brucellosis epidemiology in animals and humans in Pakistan. In total, 1,720 findings were scrutinized for being relevant, whereas duplicates, conference abstracts, reviews, and non-English articles were excluded. Authors of manuscripts with incomplete information or disclarity were contacted, and manuscripts were included only if queries were addressed. Overall, 72 peer-reviewed articles were selected for inclusion in the analysis. Information regarding geographical areas, host species, type of diagnostic tests used, and seroprevalence are presented in Tables 1, 2. For ease of understanding, the authors preferred to describe the seroprevalence by RBPT in the text.

\section{DIAGNOSIS OF BRUCELLOSIS}

Serology has been a preferred choice for the diagnosis of brucellosis in Pakistan. The most common serologic test used in Pakistan by frequency is RBPT, SAT, MRT, and indirectELISA. The use of PCR or Brucella isolation techniques occurred less frequently. RBPT is commonly used for the screening of sera because it is inexpensive. ELISA is often used as a complementary test for RBPT-positive sera, although it has been used as a single screening test at some standardized laboratories (60). Standard SAT and its modifications have been used in KPK and Punjab. These three tests are highly sensitive with lower specificity. For lactating animals, indirectmilk-ELISA and MRT methods have been used (Table 1). Both conventional and real-time PCR-based Brucella-DNA (genus and species-specific) detection and differentiation methods have been used in Pakistan. The use of isolation and microbiological characterization of brucellae is increasingly applied but still not widely practiced because of the lack of appropriate laboratories, trained personnel, and risk of laboratory-acquired infections; however, both $B$. abortus and B. melitensis have been identified by molecular/microbiological techniques $(61,62)$. Data from advanced molecular typing techniques (e.g., SNP typing, MLVA, MLST, and antimicrobial susceptibility testing) are rare $(63,64)$.

\section{BRUCELLOSIS IN ANIMALS}

Punjab is the province with the largest population of humans and livestock. The fertile river basins and the monsoon rains (JulySeptember) provide good conditions for agriculture production. Weather remains extremely varying from foggy winters (-2 
TABLE 1 | Animal brucellosis in Pakistan.

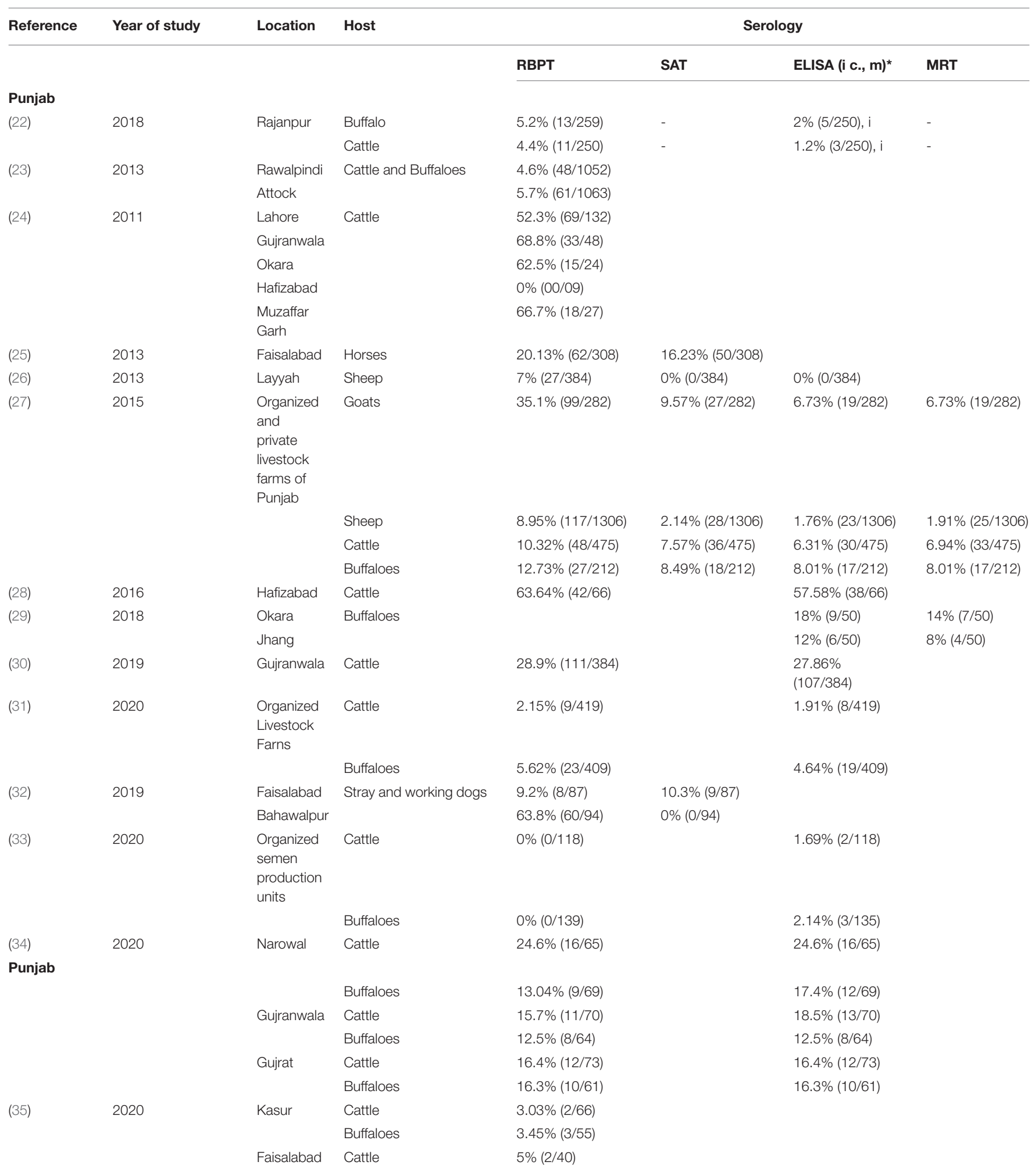


TABLE 1 | Continued

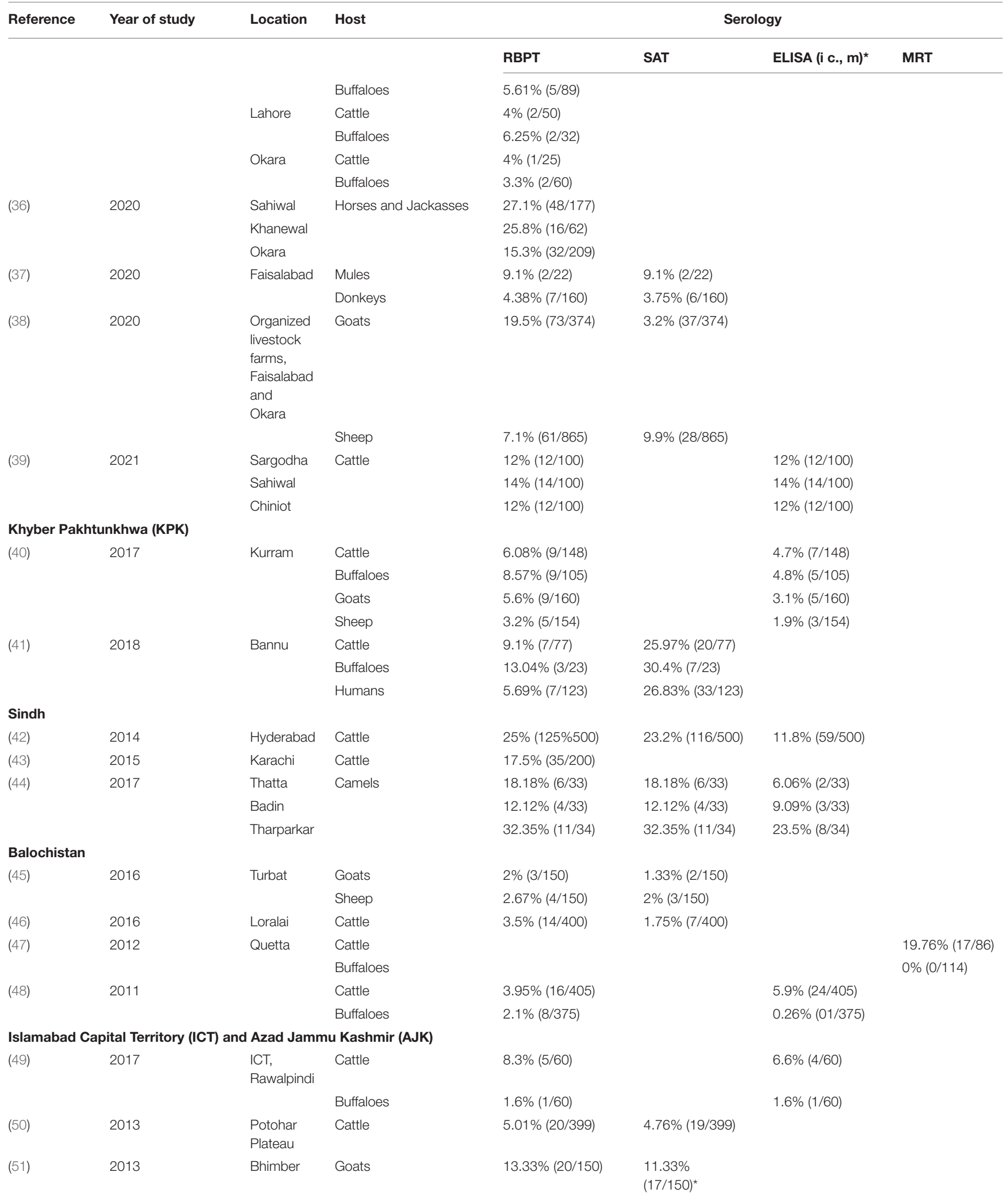

*(I, indirect; c, competitive; $m$, milk). 
TABLE 2 | Human brucellosis in Pakistan.

\begin{tabular}{|c|c|c|c|c|c|c|c|}
\hline Reference & Year & Province/territory & Area & Target group & RBPT & SAT & ELISA (i, c)s \\
\hline (52) & 2013 & Punjab & $\begin{array}{l}\text { Potohar Plateau of } \\
\text { Punjab }\end{array}$ & $\begin{array}{l}\text { Occupationally } \\
\text { exposed humans }\end{array}$ & $6.87 \%(18 / 262)$ & & \\
\hline (53) & 2016 & & Faisalabad & $\begin{array}{l}\text { Occupationally } \\
\text { exposed humans }\end{array}$ & & $38.94 \%(37 / 95)$ & \\
\hline (54) & 2016 & & Rawalpindi & Pregnant women & $5.8 \%(25 / 429)$ & & \\
\hline (55) & 2019 & & Rawalpindi & Febrile patients & $10.7 \%(28 / 261)$ & & \\
\hline (56) & 2014 & $\begin{array}{l}\text { Khyber } \\
\text { Pakhtunkhwa } \\
\text { (KPK) }\end{array}$ & Peshawar & Hospital outdoor & & $36.4 \%(455 / 1250)$ & $\begin{array}{l}60 \%(273 / 455) \\
\text { suffered from } \\
\text { acute brucellosis } \\
\text { and other } 40 \% \\
\text { (182/455) from } \\
\text { chronic brucellosis }\end{array}$ \\
\hline (57) & 2017 & & Karak & Humans & & $6 \%(12 / 200)$ & \\
\hline$(40)$ & 2017 & & Kurram & Humans & & & $3.04 \%(6 / 197)$ \\
\hline$(41)$ & 2018 & & Bannu & Humans & $6.84 \%(5 / 73)$ & $24.6 \%(18 / 73)$ & \\
\hline (58) & 2017 & & Sawat & Humans & & $\begin{array}{l}3.66 \%(11 / 300) \\
2 \%(6 / 300)\end{array}$ & \\
\hline (59) & 2021 & & Malakand & Human females & & $18.42 \%(56 / 304)$ & $27.47 \%$ \\
\hline (55) & 2019 & ICT & & Febrile patients & $9.2 \%(17 / 185)$ & & \\
\hline \multirow[t]{2}{*}{ (51) } & 2013 & Bhimber, AJK & & Humans & $9.33 \%(14 / 150)$ & $7.33 \%(11 / 150)$ & \\
\hline & & & & & & $6.0 \%(9 / 150)$ & \\
\hline
\end{tabular}

*(I,indirect; c, competitive).

$\pm 8^{\circ} \mathrm{C}$ ) to hot summers $\left(46 \pm 8^{\circ} \mathrm{C}\right)$. Because of large numbers of both conventional and intensive farming systems and comparatively better veterinary diagnostic and surveillance systems, reports of brucellosis are highest in this province (Table 1). Estimates of brucellosis from this province are highly variable depending upon the type of the diagnostic test used, animal species, farming system, and environmental factors [e.g., $0-68.8 \%$ in cattle and buffaloes, $7.1-35.1 \%$ in sheep and goats, $4.38-20.13 \%$ in horses and donkeys, and $0-10.3 \%$ for bovine (B. abortus), and $9.2-63.8 \%$ for canine (B. canis) brucellosis in dogs]. Brucellosis has been reported in all types of animal farming systems (i.e., conventional, intensive, and smallholdings) (Figure 1) (22-25, 27, 28, 30, 32-39, 65-67). Higher disease prevalence was reported in confined farming systems as compared with free-ranging livestock populations. BrucellaDNA was also detected in soil along ancient trade routes in this province (68).

Sindh is the province with the second-highest human and livestock populations and the third-largest by land size. It comprises Thar Desert in the north to fertile Indus basin in the middle and is bordered by the Arabian Sea in the south. In this province, brucellosis is reported predominantly in bovines and camels of Karachi and Hyderabad, with no reports of sheep and goats (Figure 1). Seroprevalence ranged between 17.5 and $25 \%$ in cattle and between 12.12 and $32.35 \%$ in camels (42-44).

Khyber Pakhtunkhwa is located in northwest Pakistan and ranks third for livestock and human populations. The topography is predominantly mountainous including the Hindu Kush and the Suliman ranges. Although small ruminant population are much larger than bovine populations in this province, brucellosis has been reported in both bovines and small ruminants (0-13.4\% in cattle and buffaloes and $3.2-16.67 \%$ in sheep and goats) (40, 41, 57).

Balochistan is located in southwest Pakistan, is the largest province by land area and the least populated province. It has a mountainous landscape with hot summers and cold winters. Livestock populations are predominantly small ruminants rather than large ruminants with brucellosis reported in bovines and small ruminants. Seroprevalence estimates ranged between $0.26-$ $5.9 \%$ in cattle and buffaloes and $2-2.67 \%$ in sheep and goats from districts Quetta and Turbat, respectively (Table 1) $(45,46)$.

The Islamabad Capital Territory is located in north Pakistan. Brucellosis has been widely reported in this area in bovine and small ruminant herds with seroprevalence ranging from 1.6$8.3 \%$ in cattle and buffaloes and $2.2-13.1 \%$ in sheep and goats $(23,65,69)$. Gilgit-Baltistan is an administrative territory in the north of Pakistan comprising the Himalayas, Hindu Kush, and Karakoram mountains. Reports of brucellosis in cattle (10.93\%) and wild animals have occurred in this territory (70). AJK is a selfgoverning administrative territory of Pakistan that encompasses the lower range of the Himalayan mountains. Seroprevalence of brucellosis in goats was reported to be $13.33 \%$ (Figure 1) (51, 71).

A total of 17 field isolates of $B$. abortus biovar 1 from cattle and buffaloes in Punjab and 1 isolate of $B$. melitensis from goats in KPK have been reported $(61,63)$. So far, B. melitensis has been confirmed only by real-time PCR in cattle and buffaloes but not by isolation (62). In addition, B. abortus has been diagnosed only by real-time 


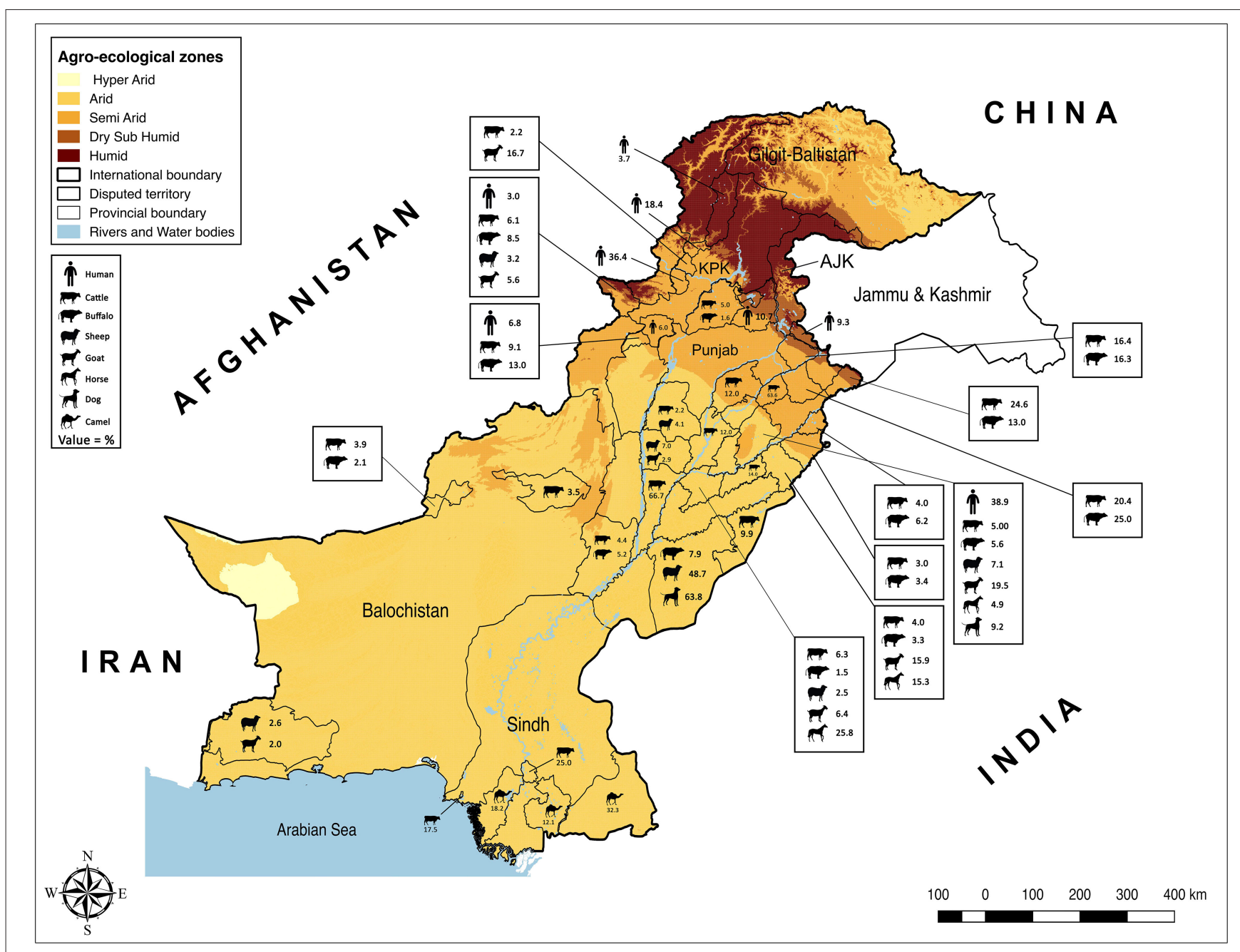

FIGURE 1 | Animal and human brucellosis in Pakistan.

PCR in sheep and goats, horses, camels, and dogs without confirmation by isolates $(32,36,69,72)$. In addition, in wildlife, only anti-smooth-lipopolysaccharide (LPS)-Brucella ( $B$. abortus and $B$. melitensis) antibodies have been reported without any PCR-based detection (73). Only one report was found describing the detection of canine brucellosis from Punjab by serology (32).

Epidemiologic variables influencing brucellosis prevalence have been studied to determine the risk. Higher disease prevalence was correlated with animal genetics as buffaloes, crossbred and exotic cattle have higher rates of brucellosis (23, $28,40,57,63)$. It has been hypothesized that a specific allele on nramp1 in Sahiwal cows increases brucellosis resistance, but data are limited so far (74). Female animals tested positive for brucellosis at a higher rate than males $(50,65)$. This observation may be influenced by the fact that (i) fewer bulls than cows are kept on farms and (ii) increasing use of artificial insemination at the farms. Greater risk for brucellosis was also associated with maturity ( $>4$ years of age), the number of pregnancies completed, increased frequency of contact with other animals $(65,75)$, retention of fetal membranes, and a history of abortion (30, 65, 75, 76). Other risk factors included the following: geographical location, management system (institution-owned, private, or general population), and herd size $(62,65,76)$. The most common cause of brucellosis infection at private-owned farms was a breach in biosecurity (i.e., the introduction of carrier animals without screening) (31). The infection often remains unidentified until abortions occur or until animals are tested positive for brucellosis in screenings.

\section{BRUCELLOSIS IN HUMANS}

To our best knowledge, in Pakistan, the first human brucellosis study was reported in 1979 (77). Currently, it has been reported 
that among all provinces, the highest numbers of patients were from Punjab (5.8-10.7\% at hospital outdoor and 6.87$38.94 \%$ in occupationally exposed) and KPK (2-36.4\% at hospital outdoor) but is still considered highly underreported and misdiagnosed (52, 53, 56, 58, 62, 78). Brucellosis generally presents as undulant fever or as chronic malaise (Table 2) (55, 79). Human patients without abortion or orchitis are treated for general febrile malaise and brucellosis is suspected when patients do not respond to routine treatments (80). The patients are often serologically positive but are negative by PCR or culture if these two approaches are performed. Delays in the onset of appropriate treatment often cause more severe or chronic disease symptoms with cardiac, intestinal, nervous, and/or pulmonary complications. Antimicrobials most frequently used to treat human brucellosis are tetracyclines, aminoglycosides, and fluoroquinolones (80). Both B. abortus and B. melitensis have been confirmed by PCR in human patients $(55,57)$. So far, no isolate has been reported from humans. It is estimated that occupational exposure, especially among veterinarians and farmers, and raw milk intake are the greatest risk factors for human brucellosis $(45,54,78,81)$. As humans are dead-end hosts, the presence of brucellosis in humans indicates a disease burden in animals. Thus, controlling the disease in animals is the most economic approach to address brucellosis in humans (9). Despite governmental initiatives, knowledge of farmers on the risks of brucellosis to date remains low in rural areas (81).

\section{DISCUSSION}

Brucellosis remains an important disease in domestic livestock and humans in Pakistan (Tables 1, 2). The review of the studies indicated a higher brucellosis prevalence in the areas with high human population, intensive animal farming, high animalhuman interaction (e.g., livestock markets, slaughterhouses, livestock breeding and dairy farms, semen production units, and veterinary hospitals), and livestock trade routes (Figure 1). In addition, consuming unpasteurized dairy milk and neglecting protective measures during handling animals and animal products at parturition/abortion, milking, and/or medication time appeared to be contributing factors. As the disease can stay asymptomatic in animals and remain undiagnosed, such practices pose a high public-health safety risk to the workers and associated people. The main cause for infections in livestock is the breach of biosecurity by the introduction of infected animals to disease-free herds (31). Animals are not screened for infectious diseases and/or are not quarantined before entry at most dairy farms. In addition, biosecurity measures of the farm premises often do not extend to other domestic animals (e.g., camels) or wildlife $(32,73)$. Their potential role is often ignored by the workers. In remote areas, the birth/aborted products of the animals are seldomly buried or disposed-off properly and are often simply drained into the sewage or nearby canals or thrown away openly. These disposals are then accessible to stray or wild carnivores. Even the farm dogs are usually fed with condemned milk and dairy products produced at the farm. Brucellae are killed by heat $\left(60^{\circ} \mathrm{C}\right.$ for $\left.10 \mathrm{~min}\right)$, ultraviolet radiation, and low-level disinfectants, but can survive up to several weeks in the presence of organic matter and soil (82). The traces of Brucella-DNA found in the soils of Punjab, where animal-human interaction was at maximum, confirm its serious menace toward public health safety and environment (68). Hence, there is the need for a "One Health" approach in controlling this disease.

The authors summarize the major obstacles in brucellosis prevention and control programs in Pakistan as follows: (i) poor implementation of strict biosecurity and standard operation procedures (SOPs) at livestock farms, (ii) poor disease surveillance and limited access to diagnostic laboratories in some areas, (iii) lack of personal protection when handling diseased animals, carcasses, or diagnostic specimens, (iv) lack of communication between human patients and medical personnel regarding disease symptoms, (v) lack of maintenance of data records on animal sales, movements, disease status, and vaccination at farms, (vi) incorrect knowledge on the effects of immunization, treatment and culling procedures/policies by farmers, and (vii) lack of appropriate laboratories for the isolation, identification, and typing of isolates.

Brucellosis is one of the priority zoonotic diseases of the national infection control and eradication program of the National Institute of Health (NIH), Islamabad, Pakistan. A national brucellosis control program was implemented in 20182023 that included capability enhancement of national and provincial laboratories, veterinary and human hospitals (26). The program implemented the use of animal tagging, register-based records, serologic monitoring, and farm biosecurity measures to control brucellosis (66). Continued strengthening of regulatory infrastructure (e.g., a laboratory network), additional training of human resources, and greater interdepartmental coordination were proposed for the brucellosis control program. Outbreaks of brucellosis can be prevented by purchasing animals from brucellosis-free herds, quarantine and testing animals before introduction into the herd, and using semen from brucellosisfree bulls. Quarantine measures for infected animals and herds must be implemented. Vaccines should be used according to their safety protocols and local veterinary legislation. An important drawback is that most serological tests are unable to differentiate between vaccinated and infected animals. Human brucellosis can be overcome by controlling animal brucellosis and ensuring the availability of pasteurized dairy milk for human consumption (21). There are still multiple challenges at the human-animalenvironment interface for controlling brucellosis in the country. Two of the greater challenges include the lack of continuous disease surveillance programs and lack of coordination between agricultural/environmental, livestock and health departments.

\section{CONCLUSION}

Brucellosis remains a persisting and challenging health hazard in Pakistan. Exotic dairy cattle producing high quantities of milk at intensive farms need higher standards of biosecurity. Occupationally exposed individuals are more prone to contract brucellosis and should adopt protective measures including regular screening. Current serological tools and 
surveillance systems must be updated and standardized especially considering rough strains of Brucella. Implementation of PCR diagnostics should be encouraged. Isolation techniques should be implemented and correspondingly the number of regional laboratories capable of safely handling samples and resulting isolates need to be increased. The potential of wildlife and other species to serve as reservoirs for brucellosis should be assessed. A nationwide vaccination program considering regional conditions/legislation should be implemented. Databases on national and regional brucellosis testing are needed. Education programs for farmers and veterinarians should be initiated with reference to the "One Health" concept to secure the acceptance of measures implemented to control brucellosis. Food safety regulations and consumer education should be strengthened. Finally, the human health sector needs to improve diagnostic facilities of

\section{REFERENCES}

1. Díaz Aparicio E. Epidemiology of brucellosis in domestic animals caused by Brucella melitensis. Brucella suis and Brucella abortus. (2013) 32:5360. doi: 10.20506/rst.32.1.2187

2. Godfroid J. Brucellosis in wildlife. Rev Sci Tech. (2002) 21:27786. doi: 10.20506/rst.21.2.1333

3. Mair TS, Divers TJ. Brucellosis in the horse. In: Mair TS, Hutchinson RE, editors. Infectious diseases of the horse. Fordham, Cambridgeshire, UK: Equine Veterinary Journal Ltd. (2009) p. 275-80.

4. Saleem MZ, Akhtar R, Aslam A, Rashid MI, Chaudhry ZI, Manzoor MA, et al. Evidence of Brucella abortus in non-preferred caprine and ovine hosts by real-time PCR assay. Pak J Zool. (2019) 51:11879. doi: 10.17582/journal.pjz/2019.51.3.sc3

5. Wernery U. Camelid brucellosis: a review. Rev Sci Tech. (2014) 33:83957. doi: 10.20506/rst.33.3.2322

6. Fensterbank R. Brucellosis in cattle, sheep and goats: diagnosis control and vaccination. Rev Sci Tech. (1986) 5:587-633. doi: 10.20506/rst.5.3.269

7. Franc KA, Krecek RC, Häsler BN, Arenas-Gamboa AM. Brucellosis remains a neglected disease in the developing world: a call for interdisciplinary action. BMC Public Health. (2018) 18:125. doi: 10.1186/s12889-017-5016-y

8. Alkahtani AM, Assiry MM, Chandramoorthy HC, Al-Hakami AM, Hamid ME. Sero-prevalence and risk factors of brucellosis among suspected febrile patients attending a referral hospital in southern Saudi Arabia (2014-2018). BMC Infect Dis. (2020) 20:1-8. doi: 10.1186/s12879-020-4763-z

9. Hull NC, Schumaker BA. Comparisons of brucellosis between human and veterinary medicine. Infect Ecol Epidemiol. (2018) 8:1500846. doi: 10.1080/20008686.2018.1500846

10. Norman FF, Monge-Maillo B, Chamorro-Tojeiro S, Pérez-Molina J-A, LópezVélez R. Imported brucellosis: a case series and literature review. Travel Med Infect Dis. (2016) 14:182-99. doi: 10.1016/j.tmaid.2016.05.005

11. Dean AS, Crump L, Greter H, Schelling E, Zinsstag J. Global burden of human brucellosis: a systematic review of disease frequency. PLoS Negl Trop Dis. (2012) 6:e1865. doi: 10.1371/journal.pntd.0001865

12. Lounes N, Cherfa M-A, Le Carrou G, Bouyoucef A, Jay M, GarinBastuji B, et al. Human brucellosis in Maghreb: existence of a lineage related to socio-historical connections with Europe. PLoS One. (2014) 9:e115319. doi: 10.1371/journal.pone.0115319

13. Abubakar M, Mansoor M, Arshed MJ. Bovine Brucellosis: Old and New Concepts with Pakistan Perspective. Pak Vet J. (2012) 32:147-55.

14. Bercovich Z. Maintenance of brucella abortus-free herds: a review with emphasis on the epidemiology and the problems in diagnosing brucellosis in areas of low prevalence. Vet Q. (1998) 20:81-8. doi: 10.1080/01652176.1998.9694845

15. Neubauer H. Brucellosis: new demands in a changing world. Prilozi. (2010) 31:209-17. brucellosis, increase patient education, and must effectively treat brucellosis cases.

\section{AUTHOR CONTRIBUTIONS}

TJ, AUK, and SS conceived the idea for this study. TJ, AUK, $\mathrm{MI}$, and QU did literature search and collection. TJ wrote the manuscript and MZS, MAK, and WA helped in technical revisions. $\mathrm{MHH}$ and AR produced the map. MS, FM, SA, AS, IK, MKM, HN, and SS critically reviewed the manuscript. All authors agreed to the final version.

\section{ACKNOWLEDGMENTS}

We acknowledge support by the Open Access Publication Initiative of Freie Universität Berlin.
16. Olsen SC, Boggiatto P, White DM, McNunn T. Biosafety concerns related to Brucella and its potential use as a bioweapon. Appl Biosaf. (2018) 23:7790. doi: 10.1177/1535676018771983

17. Anonymous, Pakistan Economic Survey 2018-19. In: M.o. Finance, editors, Economic Adviser's Wing, Finance Division, Islamabad, Government of Pakistan. (2019) 11-34.

18. McDermott J, Grace D, Zinsstag J. Economics of brucellosis impact and control in low-income countries. Rev Sci Tech. (2013) 32:24961. doi: 10.20506/rst.32.1.2197

19. Deka RP, Magnusson U, Grace D, Lindahl J. Bovine brucellosis: prevalence, risk factors, economic cost and control options with particular reference to India-a review. Infect Ecol Epidemiol. (2018) 8:1556548. doi: 10.1080/20008686.2018.1556548

20. Kollannur J, Rathore R, Chauhan R. Epidemiology and economics of brucellosis in animals and its zoonotic significance. XII International Congress of the Society of Animal Hygiene (ISAH). (2007) p. 466-8.

21. Singh B, Dhand NK, Gill J. Economic losses occurring due to brucellosis in Indian livestock populations. Prev Vet Med. (2015) 119:211-5. doi: 10.1016/j.prevetmed.2015.03.013

22. Ismail M, Ahmad I, Khan MS, Ullah S, Malik MI, Muhammad K, et al. 19. Seroprevalance of Brucella abortus in cattle and buffaloes in district Rajanpur, Punjab, Pakistan. Pure Appl Biol. (2018) 7:55664. doi: 10.19045/bspab.2018.70069

23. Ali S, Ali Q, Abatih EN, Ullah N, Muhammad A, Khan I, et al. Sero-prevalence of Brucella abortus among dairy cattle and buffaloes in Pothohar Plateau, Pakistan. Pak J Zool. (2013) 45:1041-6.

24. Shabbir MZ, Nazir MM, Maqbool A, Lateef M, Shabbir MAB, Ahmad A, et al. Seroprevalence of Neospora caninum and Brucella abortus in Dairy Cattle Herds with High Abortion Rates. J Parasitol. (2011) 97:7402. doi: 10.1645/GE-2734.1

25. Gul ST, Khan A, Ahmad M, Hussain I. Seroprevalence of brucellosis and associated hemato-biochemical changes in Pakistani horses. Pak J Agric Sci. (2013) 50:745-50.

26. Iqbal Z, Jamil H, Qureshi ZI, Saqib M, Lodhi LA, Waqas MS, et al. Seroprevalence of Ovine Brucellosis by Modified Rose Bengal Test and ELISA in Southern Punjab, Pakistan. Pak Vet J. (2013) 33:455-7.

27. Gul ST, Khan A, Ahmad M, Rizvi F, Shahzad A, Hussain I. Epidemiology of brucellosis at different livestock farms in the Punjab, Pakistan. Pak Vet J. (2015) 35:309-14.

28. Kaleem M, Durrani A, Rizwan M, Arain M, Saeed M, Bhutto Z, et al. Epidemiological investigation of outbreak of brucellosis at private dairy farm, Central Punjab-Pakistan. Adv Anim Vet Sci. (2016) 4:3947. doi: 10.14737/journal.aavs/2016/4.8.394.397

29. Khan TI, Ehtisham-ul-Haque S, Waheed U, Khan I, Younus M, Ali S, et al. Milk indirect-ELISA and milk ring test for screening of brucellosis in buffaloes, goats and bulk tank milk samples collected from two districts 
of Punjab, Pakistan. Pak. Vet. J. (2018) 38:105-8. doi: 10.29261/pakvetj/ 2018.021

30. Ullah Q, Jamil H, Lodhi LA, Qureshi ZI, Ullah S, Jamil T, et al. Brucellosis is significantly associated with reproductive disorders in dairy cattle of Punjab, Pakistan. Pak J Zool. (2019) 51:1995-7. doi: 10.17582/journal.pjz/2019.51.5.sc10

31. Jamil T, Melzer F, Saqib M, Shahzad A, Kasi KK, Hussain MH, et al. Serological and Molecular Detection of bovine brucellosis at institutional livestock farms in Punjab, Pakistan. Int J Environ Res Public Health. (2020) 17:1412. doi: 10.3390/ijerph17041412

32. Jamil T, Melzer F, Khan I, Iqbal M, Saqib M, Hussain MH, et al. Serological and molecular investigation of Brucella species in dogs in Pakistan. Pathogens. (2019) 8:294. doi: 10.3390/pathogens8040294

33. Naz S, Azeem M, Hafeez MA, Ashraf K, Asif K, Ali A, et al. Comparison of molecular and serological tests for detection of Brucella abortus in asymptomatic bovine breeding bulls. J Anim Plant Sci. (2020) 30:84552. doi: 10.36899/JAPS.2020.4.0099

34. Khan AU, Melzer F, Hendam A, Sayour AE, Khan I, Elschner MC, et al. Seroprevalence and molecular identification of Brucella spp in bovines in Pakistan-Investigating association with risk factors using machine learning. Front Vet Sci. (2020) 7:594498. doi: 10.3389/fvets.2020.594498

35. Saeed U, Ali S, Latif T, Rizwan M. Attaullah, Iftikhar A, et al. Prevalence and spatial distribution of animal brucellosis in central Punjab, Pakistan. Int $J$ Environ Res Public Health. (2020) 17:6903. doi: 10.3390/ijerph17186903

36. Hussain A, Jamil T, Tareen AM, Melzer F, Hussain MH, Khan I, et al. Serological and molecular investigation of brucellosis in breeding equids in Pakistani Punjab. Pathogens. (2020) 9:673. doi: 10.3390/pathogens 90 90673

37. Wadood F, Ahmad M, Ahmad F, Mughal D, Qamar M, Hassan Z, et al. Seroprevalence of brucellosis in donkeys and mules in Punjab, Pakistan. PakJ Sci. (2020) 72:134.

38. Shakeel M, Nawaz M, Naseer Z, Fiaz M, Khan A, Khan MI, et al. Caprine and ovine serological evidence of brucellosis in five districts of Punjab, Pakistan. Sarhad J Agric. (2020) 36:1040-5. doi: 10.17582/journal.sja/2020/36.4.1040.1046

39. Khan I, Ali S, Hussain R, Raza A, Younus M, Khan N, et al. Serosurvey and potential risk factors of brucellosis in dairy cattle in peri-urban production system in Punjab, Pakistan. Pak Vet J (2021). doi: 10.29261/pakvetj/2021.028

40. Khan AQ, Haleem SK, Shafiq M, Khan NA, Rahman SU. Seropositivity of brucellosis in human and livestock in Tribal-Kurram Agency of Pakistan indicates cross circulation. Thai J Vet Med. (2017) 47:349-55.

41. Khan A, Shafee M, Khan N, Rahman A. Rafiullah, Ali I, Khan I, Rahman SU. Incidence of brucellosis in aborted animals and occupationally exposed veterinary professionals of Bannu, Khyber Pakhtunkhwa, Pakistan. Thai J Vet Med. (2018) 48:47-54.

42. Soomro AH, Kamboh AA, Rind R, Dawani P, Sarwar M, Abro SH, et al. Study on prevalence and risk factors of brucellosis in cattle and buffaloes in district Hyderabad, Pakistan. J Anim Health Prod. (2014) 2:337. doi: $10.14737 /$ journal.jahp/2014/2.3.33.37

43. Durrani N, Rind R, Kamboh A, Habib F, Samo S. Prevalence survey of bovine brucellosis in apparently healthy dairy animals in Karachi. Pakistan J Anim Health Prod. (2015) 3:35-8. doi: 10.14737/journal.jahp/2015/3.2.35.38

44. Baloch AS, Rasheed A, Rind R, Sahito JK, Buriro R, Ayoob MF, et al. Seroprevalence of brucellosis in camels in Sindh, Pakistan. Pak J Zool. (2017) 49:391-4. doi: 10.17582/journal.pjz/2017.49.1.sc5

45. Shafee M, Ahmed N, Razzaq A, ur Rehman F, Yakoob M. Seroprevalence of brucellosis in small ruminants in Turbat (Kech), Balochistan. Lasbela U J Sci Techl. (2016):86-9.

46. Khan M, Abro SH, Abro R, Rind MR. ul Haq M, Goraya MU, Maqbool K. Occurrences of Brucella abortus in serum and milk samples of cattle in Loralai, Balochistan (a case study). Sci Int (Lahore). (2016) 28:1183-6.

47. Shafee M, Rabbani M, Sheikh AA, Ahmad MD, Razzaq A. Prevalence of bovine brucellosis in organized dairy farms, using milk ELISA, in quetta city, Balochistan, Pakistan. Vet Med Int. (2011) 2011:358950. doi: 10.4061/2011/358950

48. Shafee M, Rabbani M, Ahmad MU, Muhammad K, Sheikh AA, Awan MA, et al. Seroprevalence of bovine brucellosis using indirect ELISA in Quetta Balochistan, Pakistan. J Animal Plant Sci. (2012) 22:125-7.
49. Ahmad T, Khan I, Razzaq S, Akhtar R. Prevalence of bovine brucellosis in Islamabad and rawalpindi districts of Pakistan. Pak J Zool. (2017) 49:11236. doi: 10.17582/journal.pjz/2017.49.3.sc5

50. Farooq U, Fatima Z, Afzal M, Anwar Z, Jahangir M. Sero-prevalence of brucellosis in bovines at farms under different management conditions. Brit J Dairy Sci. (2011) 2:35-9.

51. Din AMU, Khan SA, Ahmad I, Rind R, Hussain T, Shahid M, et al. Study on the seroprevalence of brucellosis in human and goat populations of district Bhimber, Azad Jammu and Kashmir. J Anim Plant Sci. (2013) 23:113-8.

52. Ali S, Ali Q, Neubauer H, Melzer F, Elschner M, Khan I, et al. Seroprevalence and risk factors associated with brucellosis as a professional hazard in Pakistan. Foodborne Pathog Dis. (2013) 10:500-5. doi: 10.1089/fpd.2012.1360

53. Mahmood R, Ali T, Waheed U, Asif M, Khan QM. Application of serum based PCR and fluorescence polarization assay for diagnosis of brucellosis among people occupationally at risk to disease. Int J Agric Biol. (2016) 18:311-8. doi: 10.17957/IJAB/15.0099

54. Ali S, Akhter S, Neubauer H, Scherag A, Kesselmeier M, Melzer F, et al. Brucellosis in pregnant women from Pakistan: An observational study. BMC Infect Dis. (2016) 16:468. doi: 10.1186/s12879-016-1799-1

55. Saddique A, Ali S, Akhter S, Khan I, Neubauer H, Melzer F, et al. Acute febrile illness caused by Brucella abortus infection in humans in Pakistan. Int J Environ Res Public Health. (2019) 16:4071. doi: 10.3390/ijerph16214071

56. Ahmad B, Jamil S, Bashir S, Bilal M, Hassan S, Khan J. Incidence of Brucella abortus and Brucella melitensis in Peshawar and identification of active and passive infection. Life Sci J. (2014) 11:1-5.

57. Khan MZ, Usman T, Sadique U, Qureshi MS, Hassan MF, Shahid M, et al. Molecular characterization of Brucella abortus and Brucella melitensis in cattle and humans at the North-West of Pakistan. Pak Vet J. (2017) 37:360-3.

58. Ahmad H. Inamullah, Ali I, Ahmad T, Tufail M, Ahmad K, Murtaza BN. Prevalence of brucellosis in human population of district Swat, Pakistan. Pak J Zool. (2017) 49:391-3. doi: 10.17582/journal.pjz/2017.49.1.sc11

59. Niaz S, Raqeeb A, Khan A, Amir S, Zhu L, Kumar S. Status of human brucellosis in district Malakand, Khyber Pakhtunkhwa, Pakistan. J Infec Public Health. (2021) 14:423-7. doi: 10.1016/j.jiph.2019.12.013

60. Nielsen KH, Kelly L, Gall D, Nicoletti P, Kelly W. Improved competitive enzyme immunoassay for the diagnosis of bovine brucellosis. Vet Immunol Immunopathol. (1995) 46:285-91. doi: 10.1016/0165-2427(94)05361-U

61. Ali S, Ali Q, Melzer F, Khan I, Akhter S, Neubauer $\mathrm{H}$, et al. Isolation and identification of bovine Brucella isolates from Pakistan by biochemical tests and PCR. Trop Anim Health Prod. (2014) 46:738. doi: 10.1007/s11250-013-0448-6

62. Saeed U, Ali S, Khan TM, El-Adawy H, Melzer F, Khan $\mathrm{AU}$, et al. Seroepidemiology and the molecular detection of animal brucellosis in Punjab, Pakistan. Microorganisms. (2019) 7:449. doi: 10.3390/microorganisms7100449

63. Mahmood R, Waheed U, Ali T, Gopaul KK, Dainty AC, Muchowski JK, et al. Serological and nucleic acid based detection of brucellosis in livestock species and molecular characterization of Brucella melitensis strains isolated from Pakistan. Int J Agric Biol. (2016) 18:311-8. doi: 10.17957/IJAB/15.0088

64. Ali S, Akhter S, Khan I, Ahmed H, Maalik A, Neubauer H, et al. Molecular Typing of Brucella abortus Strains Isolated from cattle in different districts of Pakistan based on Bruce-Ladder-PCR and MLVA-16 Assays. Pak Vet J. (2019) 39:463-5. doi: 10.29261/pakvetj/2019.014

65. Ali S, Akhter S, Neubauer H, Melzer F, Khan I, Abatih EN, et al. Seroprevalence and risk factors associated with bovine brucellosis in the Potohar Plateau, Pakistan. BMC Res Notes. (2017) 10:73. doi: 10.1186/s13104-017-2394-2

66. Iqbal M, Fatmi Z, Khan MA. Brucellosis in Pakistan: a neglected zoonotic disease. J Pak Med Assoc. (2020) 70:1625-6. doi: 10.5455/JPMA.24139

67. Jamil T, Kasi KK, Melzer F, Saqib M, Ullah Q, Khan MR, et al. Revisiting brucellosis in small ruminants of western border areas in Pakistan. Pathogens. (2020) 9:929. doi: 10.3390/pathogens9110929

68. Ahmed R, Muhammad K, Rabbani M, Khan MS. Spatial distribution of soilborne Brucella species specific DNA in Punjab, Pakistan. Pak J Zool. (2017) 49:1739-48. doi: 10.17582/journal.pjz/2017.49.5.1739.1748

69. Ali S, Akhter S, Neubauer H, Melzer F, Khan I, Ali Q, et al. Serological, cultural, and molecular evidence of Brucella infection in small ruminants in Pakistan. J Infect Dev Ctries. (2015) 9:470-5. doi: 10.3855/jidc.5110 
70. Saher M, Mushtaq M. Ubaid-ur-Rehman Z, Shabbir M. The seroprevalence of Brucella abortus in Yak, Zo and cows in three districts of Gilgit-Baltitan, Province Wayamba. J Anim Sci. (2018) 10:1658-68.

71. Mubeen H, Khan I, Saleem MH, Akhtar R, Ali S, Saqib M, et al. Brucellosis in Mirpur, Azad Kashmir Pakistan: a livestock threat for neighboring zones. Med Weter. (2018) 74:449-51. doi: 10.21521/mw.6004

72. Fatima S, Khan I, Nasir A, Younus M, Saqib M, Melzer F, et al. Serological, molecular detection and potential risk factors associated with camel brucellosis in Pakistan. Trop Anim Health Prod. (2016) 48:17118. doi: 10.1007/s11250-016-1148-9

73. Ali S, Saleem S, Imran M, Rizwan M, Iqbal K, Qadir G, et al. Detection of Brucella antibodies in selected wild animals and avian species in Pakistan. Ind J Anim Res. (2020) 54:478-81.

74. Akhtar R, Iqbal MZ, Ullah A, Ali MM, Zahid B, Ijaz M, et al. Comparative association of slc11a1 (Nramp1) gene with susceptibility and resistance to brucellosis in various cattle and buffaloes breeds of Pakistan. Pak Vet J. (2019) 39:612-4. doi: 10.29261/pakvetj/2019.091

75. Ullah Q, Jamil T, Melzer F, Saqib M, Hussain MH, Aslam MA, et al. Epidemiology and associated risk factors for brucellosis in small ruminants kept at institutional livestock farms in Punjab, Pakistan. Front Vet Sci. (2020) 7:526. doi: $10.3389 /$ fvets.2020.00526

76. Arif S, Thomson PC, Hernandez-Jover M, McGill DM, Warriachi HM, Hayat $\mathrm{K}$, et al. Bovine brucellosis in Pakistan; an analysis of engagement with risk factors in smallholder farmer settings. Vet Med Sci. (2019) 5:390401. doi: 10.1002/vms3.165

77. Mohydin MAZ. An objective study of the incidence and prevalence of brucellosis in Lahore area of Pakistan. Pak J Med Res. (1979) 18:1.

78. Ali S, Nawaz Z, Akhtar A, Aslam R, Zahoor MA, Ashraf M. Epidemiological Investigation of Human Brucellosis in Pakistan. Jundishapur J Microbiol. (2018) 11:e61764. doi: 10.5812/jjm.61764
79. Noureen I, Hamza M, Khan SH, Khan S, Hanif M. Brucellosis as a cause of intestinal perforation. Cureus. (2020) 12:e7075. doi: 10.7759/cureus.7075

80. Hakeem M, Sana S. Brucellosis: A case report and literature review. J Postgrad Med Ed Res. (2019) 53:126-7. doi: 10.5005/jp-journals-10028-1328

81. Arif S, Thomson PC, Hernandez-Jover M, McGill DM, Warriach HM, Heller J. Knowledge, attitudes and practices (KAP) relating to brucellosis in smallholder dairy farmers in two provinces in Pakistan. PLoS ONE. (2017) 12:e0173365. doi: 10.1371/journal.pone.0173365

82. Percin D. Microbiology of Brucella. Recent Pat Antiinfect Drug Discov. (2013) 8:13-7. doi: 10.2174/1574891X11308010004

Conflict of Interest: The authors declare that the research was conducted in the absence of any commercial or financial relationships that could be construed as a potential conflict of interest.

Publisher's Note: All claims expressed in this article are solely those of the authors and do not necessarily represent those of their affiliated organizations, or those of the publisher, the editors and the reviewers. Any product that may be evaluated in this article, or claim that may be made by its manufacturer, is not guaranteed or endorsed by the publisher.

Copyright () 2021 Jamil, Khan, Saqib, Hussain, Melzer, Rehman, Shabbir, Khan, Ali, Shahzad, Khan, Iqbal, Ullah, Ahmad, Mansoor, Neubauer and Schwarz. This is an open-access article distributed under the terms of the Creative Commons Attribution License (CC BY). The use, distribution or reproduction in other forums is permitted, provided the original author(s) and the copyright owner(s) are credited and that the original publication in this journal is cited, in accordance with accepted academic practice. No use, distribution or reproduction is permitted which does not comply with these terms. 